\title{
Amperometric biosensor for lactate analysis in wine and must during fermentation
}

\author{
Shkotova L.V.(1), Goriushinana T.B. (1), Tran-Minh CANH(2), ChOVElon J EaN- \\ MARC $^{(3)} *$, SOLDATKINA.P.(1), DZYADEVYCH S.V.(1)
}

(1) Laboratoire d'Electronique Biomoléculaire, Institut de Biologie Moléculaire et de Génétique, Académie nationales des Sciences d'Ukraine, 150 Zabolotnogo Str., Kyiv 03143, Ukraine

(2) Ecole Nationale Supérieure des Mines de Saint Etienne, Centre SPIN ; Département PMMC ; 158 Cours Fauriel ; 42023 Saint-Étienne Cedex 2, France

(3) IRCELYON, Institut de Recherches sur la Catalyse et l'Environnement de Lyon, UMR CNRS 5256, Université Lyon 1, CNRS, 2 avenue Albert Einstein, 69626 Villeurbanne, France

\begin{abstract}
A lactate oxidase-based amperometric biosensor is designed for lactate determination. Two methods of lactate oxidase immobilization on the surface of commercial SensLab platinum printing electrodes are compared. The sensor with lactate oxidase immobilized by physical adsorption in Resydrol polymer is shown to have both narrower dynamic range (0.004$0.5 \mathrm{mM}$ lactate) and higher sensitivity $(320 \mathrm{nA} / \mathrm{mM})$ as compared with that immobilized in poly(3,4-ethylenedioxythiophene) by electrochemical polymerization (0.05-1.6 mM and $60 \mathrm{nA} / \mathrm{mM}$ respectively). The operational stability of the biosensors developed is studied; the immobilization method is shown to be of no influence. The lactate content in wine and in wine material during fermentation is analyzed. The data obtained by amperometric lactate biosensor correlated with those of standard chromatography. The biosensor developed can be used in food industry for control and optimization of process of wine fermentation as well as for control of wine quality.

Keywords:

Lactate oxidase; Amperometric biosensor; Resydrol; Lactate; Wine; Electrochemical polymerization

\section{Introduction}

Wine as an element of food industry at all stages of production should be exposed to technical and chemical control aimed at determination of components of must and wine which influence the final product quality [1].

The formation and transformation of organic acids at must fermentation and wine production are of great importance in wine-making. Biochemical processes caused by yeast enzymes are significant to achieve necessary quality of wine materials. Knowledge on the mechanisms of formation of secondary products ensures their proper regulation toward wine enrichment in the beneficial components which determine wine race and flavour [2]. Organic acids also protect wine against bacterial diseases. In acid medium, redox processes are slower which inhibits wine ripening but prevents ferrophosphate turbidity.
\end{abstract}

*Auteur à qui la correspondance devait être adressée : jean-marc.chovelon@univ-lyon1.fr 
The acids due to reaction with spirits form esters and thus take part in providing race of wine. However, high content of some acids influences wine flavour badly. An increased content of malic acid is considered to result in taste of green berries. Therefore, in practice significant importance has conversion by lactic bacteria of dicarboxylic malic acid into monocarboxylic lactic acid since the latter is characterized by softer taste and thus harmonizes wine taste. At the same time, an excess of lactic acid has also a negative effect on wine, especially if fermentation is caused by heterotrophic lactic bacteria because of formation of acetate, diacetyl and other substrates which spoil wine race [2].

Lactate formation at normal alcohol fermentation was proved by S. Durmishidze [3]. It is a secondary product of anaerobic fermentation, resulting from reduction of its predecessor, pyruvate, in the presence of $\mathrm{NAD} \cdot \mathrm{H}_{2}$. Lactate can be also generated in another way - from glutamate and alanine [2]. Permanent, simultaneous and selective lactate monitoring (preferably, along with other key components) is important in wine-making since this parameter not only determines quality and special odour of wine but if necessary, allows interfering into fermentation efficiently, thus preventing significant economic losses.

Actually, there are classic methods for lactate determination: liquid chromatography [4], colorimetry, and enzymatic methods [4] and [5]. However, they use rather complicated apparatus and depend on analyte volume, therefore alternative approach is required.

Biosensors can be considered as promising alternative if they are inexpensive and reliable, provided simple, fast and cheap procedure, and, what is of essential importance, profitability [6] and [7].

Now a few biosensors are applied to test quality of raw material in food production despite the fact that they are advantageous in fast response and high specificity as well as in low cost and easy data processing. Therefore, development of biosensors assigned for control of food quality is now in focus of scientific research. Remarkable progress in this field revealed during recent years is a result of up to date achievements in micromechanics as well as in increasing sensitivity and quality of associated electric equipment.

Lactate biosensors can be based on two enzymes, either lactate oxidase or lactate dehydrogenase [8], [9], [10] and [11]. However, the latter require the presence of cofactor $\mathrm{NAD}^{+}$which complicates analysis and increases its cost. Moreover, a supplementary enzyme, glutamate pyruvate transaminase, is necessary for efficient reaction, thus the price of analysis raises still more [12]. In work [13] and [14] authors described sensors based on lactate dehydrogenase for lactate determination which required presence of hexacyanoferrate (III) in the samples that also complicates analysis.

The biosensors based on immobilized lactate oxidase (LOX) are preferable to those based on lactate dehydrogenase because, in contrast to the latter, there is a natural cofactor FAD in the LOX composition. A number of lactate biosensors have been described in literature, e.g. the biosensor based on lactate oxidase immobilized into polyphenilethylene diamine ultrathin polymer membrane for the lactate analysis in blood [15]. Because of a miniature sensor, the volume of electrochemical cell where the measurements were carried out, was only a few nanoliters. However, it had poor operational stability. There was some information [16] and [17] about the multisensors capable of determining simultaneously lactate and other components of physiological liquids. Standard hydrogels were used to form the polymer matrixes, operational stability was from two weeks to two months.

Different polymer matrixes can be utilized for LOX immobilization into membrane [18], [19] and [20]. Recently it was shown that usage of 2,6-dihydroxynaphthalene copolymerized with 2-(4-aminophenyl)-ethylamine makes it possible to obtain high sensor sensitivity to lactate $(10 \mu \mathrm{M})$ [18]. Using nylon matrix as a base of sensitive membrane other authors developed a lactate biosensor based on immobilized lactate oxidase with high sensitivity $(2 \mu \mathrm{M})$ which operated stably for a week [21].

This work was aimed at development of the amperometric biosensor based on the platinum SensLab electrode (SensLab GmbH, Leipzig, Germany) with immobilized lactate oxidase for lactate determination in must during its fermentation and in wine. 


\section{Materials and methods}

\section{II.1. Chemicals}

Enzyme lactate oxidases from Pediococcus species with specific activity $31 \mathrm{U} / \mathrm{mg}$ and $49 \mathrm{U} / \mathrm{mg}$ were obtained from Sigma-Aldrich Chemie $\mathrm{GmbH}$ (Germany) and with specific activity $40 \mathrm{U} / \mathrm{mg}$ was obtained from Fluka (Switzerland). As the polymer matrix for enzyme deposition, Resydrol AY 498 w/35WA (Slutia Austria GmbH) was used. For electrochemical deposition the monomer 3,4-ethylenedioxythiophene (EDT) from Baytron M (Germany) and polyethylene glycol 1450 from Sigma-Aldrich Chemie $\mathrm{GmbH}$ (Switzerland) were used. Besides, we used the following chemicals: $\mathrm{Na}_{2} \mathrm{HPO}_{4} \cdot 7 \mathrm{H}_{2} \mathrm{O}, \mathrm{KH}_{2} \mathrm{PO}_{4}, \mathrm{KCl}, \mathrm{NaOH}$ and lactate from Sigma-Aldrich Chemie GmbH (Germany). All chemicals were analytical grade.

\section{II.2. Apparatus}

All electrochemical experiments were performed using a conventional three-electrode system with the SensLab electrode (SensLab GmbH, Leipzig, Germany) which combines all three electrodes, i.e. platinum working, auxiliary and reference ones [22]. The electrodes produced were previously tested with regard to their reproducibility and reliability by cyclic voltamperometry within the potential range of $0-300 \mathrm{mV}$ (speed of potential involute was $20 \mathrm{mV} / \mathrm{s}$ ) using potentiostate PI-50-11 (Ukraine).

Amperometric measurements were carried out in $5 \mathrm{ml}$ electrochemical cell at a constant potential using the same potentiostate, programmer PR-8 (Ukraine) and VoltaLabTM 21 system (potentiostate/galvanostate PGP201 Radiometer, Copenhagen, Netherlands) controlled by the VoltaMaster 11 programme, production of Radiometer Co. (Copenhagen, Netherlands).
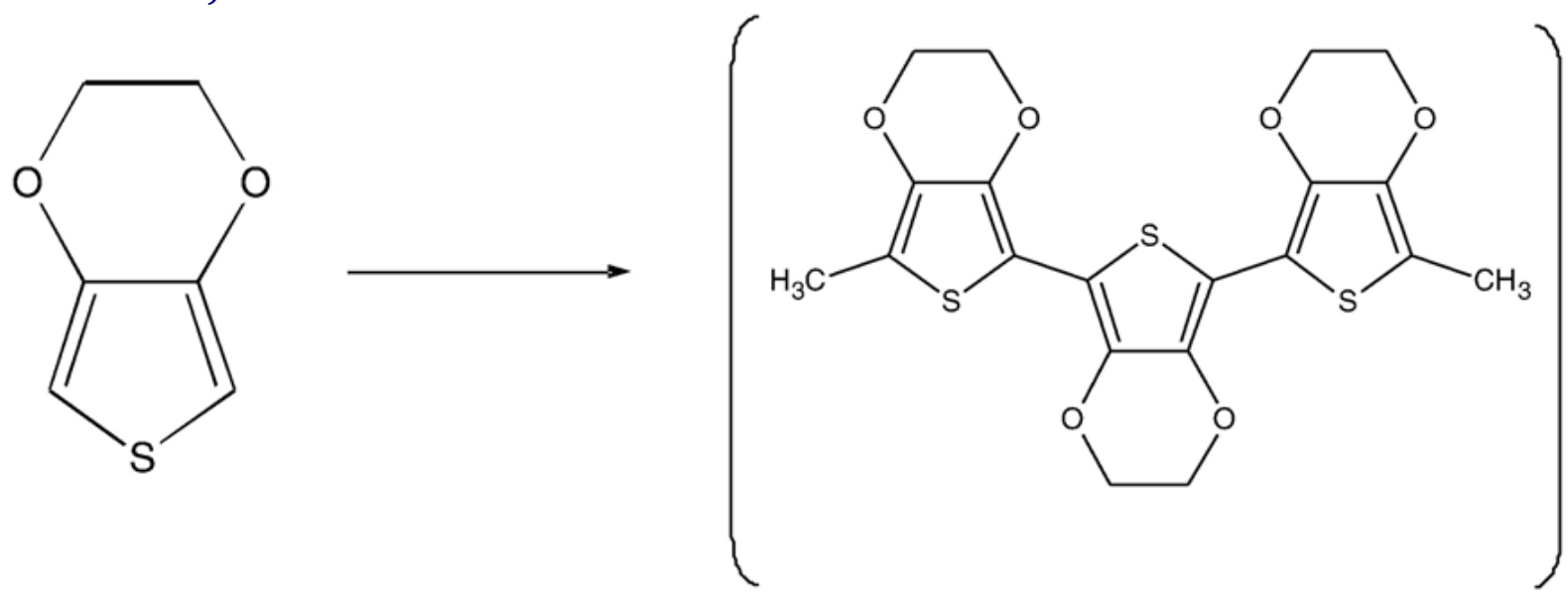

\section{EDT}

PEDT

Figure 1: Basic scheme of PEDT polymerization [23]

\section{II.3. Electrochemical LOX immobilization onto surface of SensLab electrodes}

Electrochemical polymerization is of special interest due to its manufacturability. It allows choosing and preserving matrix size, shape and thickness, assures direct control over precipitation.

Poly(3,4-ethylenedioxythiophene) (PEDT) is one of the polythiophenes, conductive polymers with new and noteworthy characteristics. They demonstrated faint conductivity, low charge alteration, high stability, and valuable ability of film formation. The EDT monomer, the Baytron commercial product, recently came into the market from Bayer AG Co. (Germany). The polymer form and mechanism of polymer structure modification are demonstrated in Figure 1 [23] and Figure 2 [24].

Figure 2: Suggested mechanism of modification of PEDT structure at electrochemical polymerization [24]. 
A homogenous film PEDT is fixed on the surface of the working electrode, electrochemically polymerized 3,4-ethylenedioxythiophene (EDT) upon neutral $\mathrm{pH}$ and temperature. Film is formed preferably in aqueous and, if possible, hydrophilic polymers of polyvinyl pyrrolidone (PVP) or polyethylene glycol type dissolved in water with electropolymerizing solution. Hydrophilic properties of the deposited polymer rise in this case. Whether it would be oxidation or reduction depends on the potential applied since it controls generation of a positive charge in the polymer structure. It is proved for PEDT that polyanions as oligonucleotides can be effectively kept in the polymer net which acts at weak electronic strength [25]. Comparison of polyacetylene with polypyrrole and polythiophene (all charged positively) demonstrates higher stability of the latter two which can be supposed to be a result of the presence of positive charges of nitrogen or sulfur

A mixture of $10^{-2} \mathrm{M} 3,4-\mathrm{EDT}, 10^{-3} \mathrm{M}$ polyethylene glycol and $35 \mathrm{mg} / \mathrm{ml}$ lactate oxidase prepared in $20 \mathrm{mM}$ phosphate buffer, $\mathrm{pH}$ 6.2, was used for electrochemical polymerization. It was performed applying potential from +0.2 to $+1.5 \mathrm{~V}$ at a speed of $0.1 \mathrm{~V} / \mathrm{s}$ during 15 cycles.

The cyclic voltamperogramme of PEDT electrochemical synthesis (Figure 3) demonstrates decrease of peak values at each next cycle as a result of polymer film formation on the working electrode surface.

\section{II.4. LOX immobilization into polymer film Resydrol by physical adsorption}

Commercial resin Resydrol AY 498 w/35WA (Slutia GmbH Austria) was used as a polymer matrix for enzyme deposition. These resins mainly consist of acryl copolymers and acrylic ethers which determine solubility and protonation rate at definite $\mathrm{pH}$ [27] and [28].

For LOX immobilization into polymer film Resydrol, $30 \mathrm{mg} / \mathrm{ml}$ LOX solution prepared in $10 \mathrm{mM}$ phosphate buffer, $\mathrm{pH}$ 7.2, was mixed at a ratio of 1:3 with $300 \mu \mathrm{l}$ of Resydrol dissolved in $1 \mathrm{ml}$ of water. Due to homogeneity and low viscosity of the mixture obtained it could be easily collected and deposited on the working electrode surface. For polymerization, the sensor was maintained during $2 \mathrm{~h}$ at $+4{ }^{\circ} \mathrm{C}$.

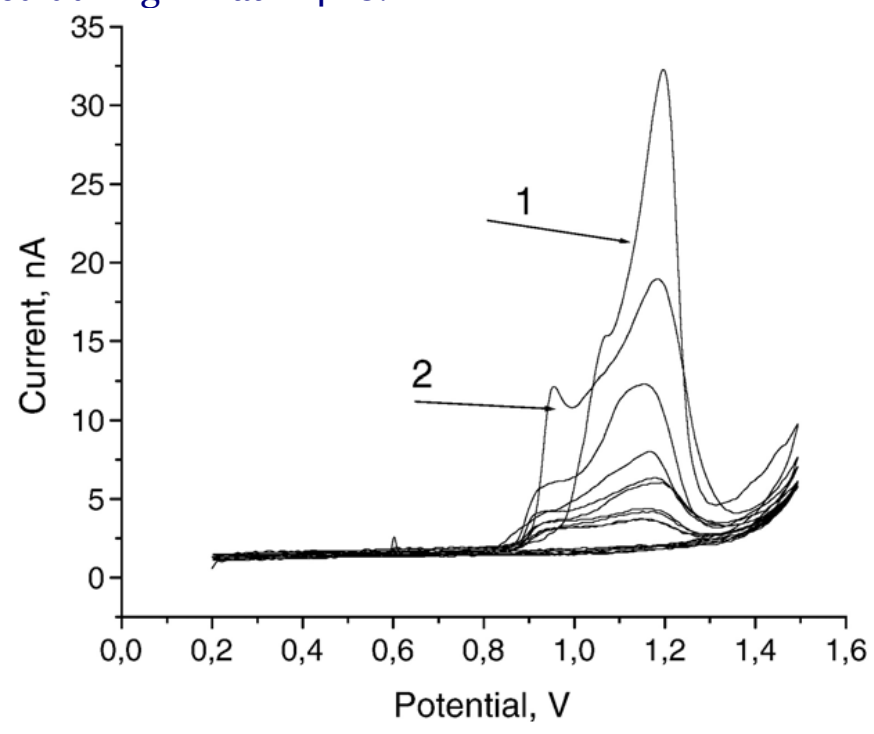

Figure 3: Cyclic voltamperogramme of electrochemical synthesis of poly(3,4-ethylenedioxythiophene) in $0.02 \mathrm{M}$ phosphate buffer, $\mathrm{pH} 6.2$, involute speed $0.1 \mathrm{~V} / \mathrm{s}, 1,2$ are cycle numbers.

\section{II.5. Lactate determination in model solutions}

The substrate concentration was measured in $100 \mathrm{mM}$ buffer solution $\mathrm{KH}_{2} \mathrm{PO}_{4}-$ $\mathrm{Na}_{2} \mathrm{HPO}_{4} \cdot 12 \mathrm{H}_{2} \mathrm{O}, \mathrm{pH} 7.2$, at room temperature in open vessel at intensive stirring. The concentrations were varied by addition of certain aliquots of concentrated solutions.

\section{II.6. Lactate determination in wine and must}

Lactate was measured in four samples of different wines produced under conditions of micromanufacture in the Magarach Institute of grapes and wine and the Magarach 
agricultural firm (Crimea, Ukraine) as well as in 29 samples of wine materials at various stages of their fermentation.

Pasteurized unsulfizated must from the Rkaziteli grapes of 2003 year's harvest produced in the Sofia Perovskaya close corporation (Sevastopol, Crimea, Ukraine) was used for fermentation. $2 \%$ of yeast culture $1-527$ from the National microorganisms collection of the Magarach Institute of grapes and wine was added to the must.

The must fermentation was processed in the apparatus of periodic operation, volume of $10 \mathrm{l}$, sealed with a cotton pug under semi-anaerobic conditions at temperatures of $16-28{ }^{\circ} \mathrm{C}$ and $26^{\circ} \mathrm{C}$. The apparatus was thermostated by the I130 air thermostat. The fermentation must was stirred once or twice daily. The periodicity of sampling was the same, at the moment the must temperature was measured. The samples were centrifuged at $5000 \mathrm{rpm}$, the supernatant was further analyzed.

Reference control measurement of the lactate concentration in must at fermentation and in wine was carried out by ion chromatography [1] and [29].

II.7. Lactate measurement in wine and must by amperometric biosensor

The measurements were performed in an open vessel of intensively stirred $100 \mathrm{mM}$ phosphate buffer solution, $\mathrm{pH}$ 7.2. To obtain the calibration curve, certain aliquots of concentrated lactate solution were added to electrochemical cell. A wine sample of $5 \mu \mathrm{l}$ volume, the lactate concentration in which to be measured was then introduced into the vessel, thus dilution ratio equaled 1000. The lactate concentration in wine sample was determined by the response obtained in about 1 min according to the calibration curve.

After obtaining each response, the sensor was washed with buffer solution up to output signal stabilization.

\section{Results and discussion}

The basic enzymatic reaction in lactate determination by amperometric biosensors based on lactate oxidase is:

$$
\text { L-lactate }+\mathrm{O}_{2} \stackrel{\text { LOX }}{\longrightarrow} \text { pyruvate }+\mathrm{H}_{2} \mathrm{O}_{2}
$$

The lactate hydrolysis is accompanied by accumulation of electrically active substance, hydrogen peroxide, whose decomposition results in generation of electrons registered by amperometric transducer.

In the work presented, the enzyme was immobilized onto transducer surface by two methods, by physical adsorption in Resydrol and by electrochemical deposition in PEDT.

Prior to the investigation, the biosensor should be optimized as to its analytical characteristics for further operation in real samples. As the first step, optimum $\mathrm{pH}$ of the biosensor based on immobilized LOX was defined (Figure 4). The results obtained were in accordance with those presented in literature, i.e. 7.0-7.5 [30], [31] and [32]. As seen in Figure 4, in our experiments optimal $\mathrm{pH}=7.2$ in case of Resydrol while it is 7.4 for PEDT, so the $\mathrm{pH}$ optimal value of lactate biosensor is not influenced by the method of immobilization. 


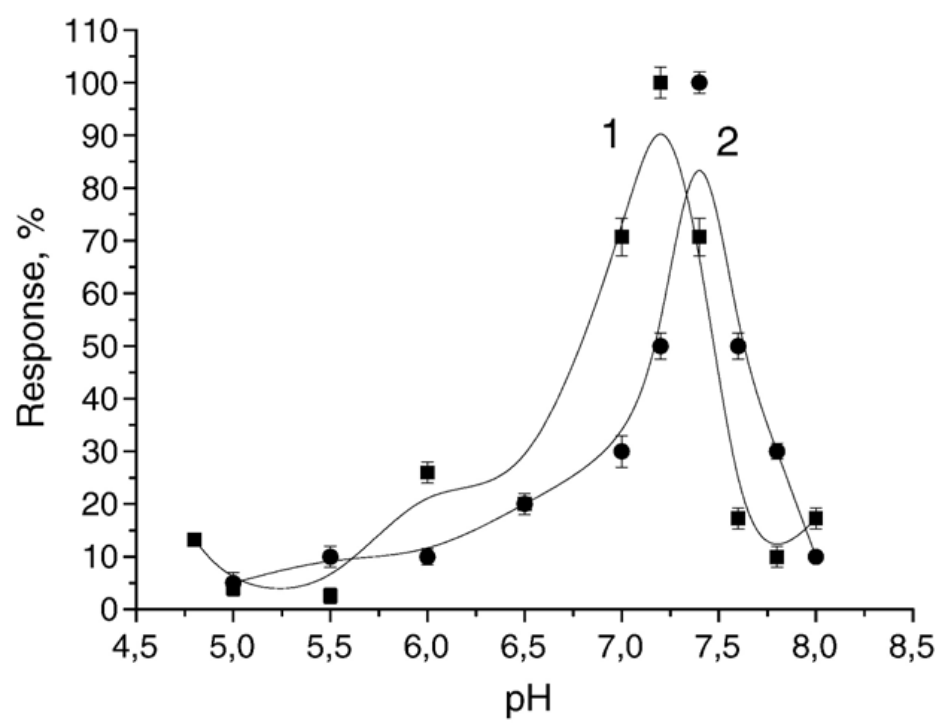

Figure 4: Response dependence for amperometric biosensors based on lactate oxidase immobilized in Resydrol polymer by physical adsorption (1) and in PEDT polymer by electrochemical polymerization (2) on $\mathrm{pH}$ of solution. Measurement was carried out in $100 \mathrm{mM}$ phosphate buffer, $\mathrm{pH} 7.2$, potential $+300 \mathrm{mV}$ with regard to internal reference electrode.

As has been earlier reported [33] and [34] the background electrolyte concentration in buffer as well as buffer capacity have no effect on working characteristics of amperometric glucose biosensor. Since this situation is typical for enzyme biosensors, no further study on the issue for lactate biosensor was carried out.

The stability of the sensor based on immobilized LOX was studied. As a result, the response in case of LOX immobilized in Resydrol was shown to decrease by $2.5 \%$ daily (Figure 5, curve 1) while that for electrochemically deposited in PEDT - by 3\% daily (Figure 5, curve 2), i.e. the immobilization method has no effect on the sensor stability.

The developed amperometric biosensor based on LOX immobilized in Resydrol by physical adsorption was characterized in linear dependence of the biosensor response on lactate concentration within the range of $0.004-0.5 \mathrm{mM}$, while for the biosensor based on LOX immobilized in PEDT by electrochemical deposition this range was 0.05-1.6 mM (Figure 6). Consequently, the former has a narrower dynamic range of lactate determination at higher sensitivity as compared with the latter. This phenomenon can be elucidated by formation of a more compact membrane in case of the enzyme immobilization by electrochemical deposition which results in decrease of response, on the one hand, and in the range extension - on the other.

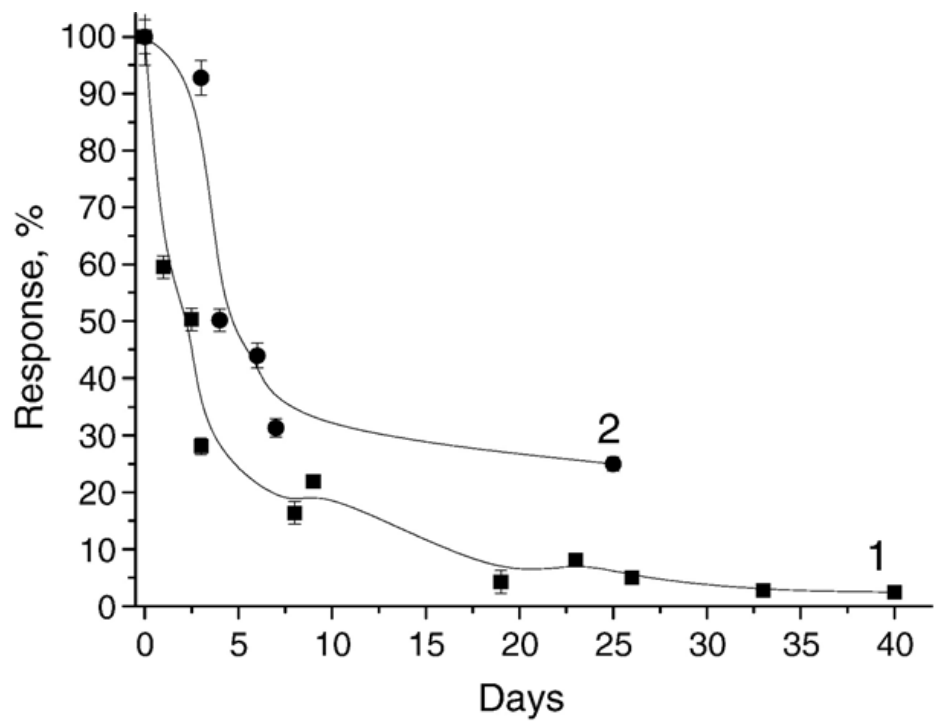


Figure 5: Stability of amperometric biosensors based on LOX immobilized in Resydrol (1) and in PEDT by electrochemical polymerization (2). Measurement was carried out in $100 \mathrm{mM}$ phosphate buffer, pH 7.2, potential $+300 \mathrm{mV}$ with regard to internal reference electrode.

Figure 6: Calibration curve of amperometric biosensor based on platinum printed SensLab electrode with LOX immobilized in Resydrol by physical adsorption (1) and in PEDT by electrochemical polymerization (2). Measurements were carried out in $100 \mathrm{mM}$ phosphate buffer, $\mathrm{pH} 7.2$, potential $+300 \mathrm{mV}$ with regard to internal reference electrodeOptimization of the amperometric lactate biosensor sets in motion its application for the lactate analysis in real samples. As a subject of investigation four wine samples and 29 samples of must at various fermentation stages were taken. All of them were the production of the Magarach Institute of grapes and wine. The lactate concentration during fermentation and in finished wine was measured by two methods - the developed amperometric biosensor with immobilized lactate oxidase and ion chromatography. A good correlation of results for wine samples was showed (Table 1). However, for samples of must at various stages of fermentation some discrepancy of results was obtained, especially for first days of fermentation (Table 2). It could be connected with fact that at first days of fermentation a lactate concentration is very small, and sensitivity of amperometric biosensors is insufficient for low lactate concentrations. 
Table 1: Analysis of lactate concentration in wine

\begin{tabular}{|l|l|l|}
\hline Sample & $\begin{array}{l}\text { Lactate concentration, } \\
\text { g/l }( \pm 0.1) \text { ion } \\
\text { chromatography }\end{array}$ & $\begin{array}{l}\text { Lactate concentration, } \\
\text { g/l ( } \pm 0.1) \text { biosensor }\end{array}$ \\
\hline Cabernet Sauvignon (dry red) & 2.5 & 2.55 \\
\hline Chardonnay (dry white) & 3 & 3.74 \\
\hline Sherry strong Magarach (white) & 1.1 & 1.62 \\
\hline Danko sweet wine (red) & 0.1 & 0.21 \\
\hline
\end{tabular}

Table 2: Analysis of lactate concentration during wine fermentation

\begin{tabular}{|c|c|c|c|}
\hline No. of sample & Day & \multicolumn{2}{|c|}{ Lactate concentration, g/l } \\
\hline & & Ion chromatography & Biosensor \\
\hline 1 & $\mathrm{O}$ & 0.04 & 0.31 \\
\hline 2 & 1 & 0.04 & 0.82 \\
\hline 3 & 1.3 & 0.07 & 0.32 \\
\hline 4 & 2 & 0.14 & 0.99 \\
\hline 5 & 3 & 0.21 & 0.26 \\
\hline 6 & 4.1 & 0.21 & 0.64 \\
\hline 7 & 5 & 0.21 & 0.29 \\
\hline 8 & 6 & 0.21 & 0.31 \\
\hline 9 & 7 & 0.35 & 0.35 \\
\hline 10 & 8 & 0.21 & 0.44 \\
\hline 11 & 9 & 0.14 & 0.77 \\
\hline 12 & 10 & 0.21 & 0.25 \\
\hline 13 & 11 & 0.28 & 0.23 \\
\hline 15 & 13 & & 0.31 \\
\hline
\end{tabular}

\section{Conclusion}

On the purpose of development of amperometric biosensor for lactate determination, two methods of immobilization of lactate oxidase onto the surface of commercial platinum printed electrodes SensLab were compared. The sensor with LOX immobilized in polymer Resydrol by physical adsorption is shown to have both narrower dynamic range and higher sensitivity in comparison with the biosensor with LOX immobilized in polymer PEDT by electrochemical deposition. The analytical characteristics of these biosensors are studied, the immobilization method is shown to be of no influence on biosensor operational stability and $\mathrm{pH}$ optimal value. The lactate concentration both in must during its fermentation and in finished wine was analyzed. The results obtained by the amperometric lactate biosensor correlated with those measured by standard method of ion chromatography.

Thus, the biosensor developed can be recommended in food industry to monitor and optimize the fermentation process and to control quality of finished wine.

\section{Acknowledgements}

Part of this work was financially supported by National Academy of Sciences of Ukraine in the frame of Scientific and Technical Program "Sensors systems for medical-ecological and industrial-technological problems".

\section{References}

[1] V.O. Rusakov, Chemistry and Biochemistry of Wine, USUFT, Kyiv (2001).

[2] A.K. Rodopulo, Biochemistry of Wine-making, Food industry, Moscow (1971). 
[3] S.V. Durmishidze and O.T. Khachidze, Biochemistry of Vine, Mechiereba, Tbilisi (1985).

[4] Office International de la Vigne et du Vin (OIV), Recueil des methods internationles d'analyse des vine et des mouts, OIV, Paris (1990) 368 p.

[5] J. Ribereau-Gayon, E. Peynaud, P. Sudraud and P. Ribereau-Gayon, Dunod Paris 1 (1972), p. 591.

[6] J.H.T. Luong, P. Bouvrette and B. Keith, TibTech. 15 (1997), p. 369

[7] J.H.T. Luong, C.A. Groom and K.B. Male, Biosens. Bioelectron. 6 (1991), p. 547.

[8] A. Avramescu, T. Noguer, V. Magearu and J-L. Marty, Anal. Chim. Acta 433 (2001), p. 81.

[9] A. Avramescu, T. Noguer, M. Avramescu and J-L. Marty, Anal. Chim. Acta 458 (2002), p. 203

[10] S. Miertus, J. Katrlk, A. Pizzariello, M. Stred'ansky, J. Svitel and J. Svorc, Biosens. Bioelectron. 13 (1998), p. 911.

[11] J. Lima, T. Lopes and A. Rangelb, Anal. Chim. Acta 366 (1998), p. 187.

[12] F. Noll, Biochem. Z. 346 (1966), p. 41.

[13] H. Durliat, C. Causserand and M. Comtat, Anal. Chim. Acta. 231(1990), p. 309.

[14] M. Montagne, H. Durliat and M. Comtat, Anal. Chim. Acta. 278 (1993), p. 25.

[15] M.M. Rhemrev-Boom, M.A. Jonker, K. Venema, G. Jobst, R. Tiessena and J. Korf, Analyst 126 (2001), p. 1073.

[16] F. Palmisano, R. Rizzi, D. Centonze and P.G. Zambonin, Biosens. Bioelectron. 15 (2000), p. 531.

[17] I. Moser, G. Jobst and G.A. Urban, Biosens. Bioelectron. 17 (2002), p. 297.

[18] M. Badea, A. Curulli and G. Palleschi, Biosens. Bioelectron. 18 (2003), p. 689.

[19] B. Serra, A.J. Reviejo, C. Parrado and J.M. Pingarron, Biosens. Bioelectron. 14 (1999), p. 505 .

[20] A. Chaubey, K. Pande, V.S. Singh and B.D. Malhotra, Anal. Chim. Acta 407 (2000), p. 97.

[21] M. Esti, G. Volpe, L. Micheli, E. Delibato, D. Compagnone, D. Moscone and G. Palleschi, Anal. Chim. Acta 513 (2004), p. 357.

[22] L.V. Shkotova, E.A. Slast'ya, T.A. Zhylyakova, A.P. Soldatkin, W. Schuhmann and S.V. Dzyadevych, Ukr. Biochem. J . 77 (1) (2005), p. 96.

[23] A. Khan and S.P. Armes, Langmuir 15 (1999), p. 3469.

[24] S. Garreau, G. Louarn, J.-P. Buisson, G. Froyer and S. Lefrant, Macromolecules 32 (1999), p. 6807.

[25] B. Piro, M.-C. Pham and T. Ledoan, J . Biom. Mat. Res. 46 (1999), p. 566.

[26] G. Heywang and F. Jonas, Adv. Mater. 4 (1992), p. 116.

[27] C. Kurzawa, Ph.D. thesis, Ruhr-Universitat Bochum, 2001.

[28] C. Kurzawa, A. Hengstenberg and W. Schuhmann, Anal. Chem. 74 (2002), p. 355.

[29] N.A. Mekhuzl, International Book of methods of analysis of wine and must, Food industry, Moscow (1993).

[30] G. Bardeletti, F. Sechaud and P.R. Coulet, Anal. Chim. Acta 187 (1986), p. 47.

[31] B. Serra, A.J. Reviejo, C. Parrado and J.M. Pingarron, Biosens. Bioelectron. 14 (1999), p. 505 .

[32] K. Matsumoto, H. Matsubara, M. Hamada, H. Ukeda and Y. Osajima, J. Biotechnol. 14 (1990), p. 115.

[33] L.V. Danileyko, O.N. Schuvaylo, V.N. Arkhypova, A.P. Soldatkin and S.V. Dzyadevych, Biopolimers Cell 19 (2003), p. 76.

[34] L.V. Shkotova, A.P. Soldatkin and S.V. Dzyadevych, Ukr. Biochem. J. 76 (3) (2004), p. 114. 